\title{
STUTTERING AS LEARNED BEHAVIOUR
}

\section{Theoretical and therapeutic implications}

By MARGARET MARRS, B.A., Log. (Rand), L.T.C.In

No theory concerning stuttering is justifiable without practical therapeutic implications. It is for this reason that I like to consider stuttering as a learned pattern of behaviour, the assumption being that what is learned can be unlearned, if not by the organism itself, then with the aid of therapeutic techniques.

In attempting to discuss various authoritys' theories in learning terms I have divided theories into "exogenous" and "endogenous" groups-exogenous being these theories which postulate that the stuttering originated outside the organism; and endogenous being those which suggest that stuttering begin within the organism.

It is self-explanatory that all the exogenous theorists (e.g., Blumel (1); Johnson (2); Stein (3) Fletcher (4)) would agree that something happens to the organism after birth which results in stuttering, i.e., that he learns this stuttering pattern of behaviour.

Travis, 1931 (5), who is probably the most extreme of the endogenous group, sites unfavourable environmental factors as being contributory to the development of stuttering - "such accessory factors as prolonged emotional excitement, exhaustion and emotional shock may act upon the sub-soil of an insufficient cerebral dominance, and become the precipitating factors which allow the predisposing factors to manifest themselves in observable behaviour." He regards secondary symptoms as "largely reactions to, rather than an intergal part of, the stuttering condition."

Writers who believe in a precipitating condition which acts upon a predisposing organism (e.g., Karlin (6), in his "Psycho-somatic Theory; van Riper (7), in his predisposingprecipitating and maintaining factors theory ; Kingdon Ward (8), in her theory of environment acting upon an organism with a "residual diathesis") all take into account the part played by the environment on the weak organism. These writers would also support the view that learning plays a large part in stuttering.

If the actual stutterer can be divided into the original "block" or 'repetition," plus the "secondary symptom," we can consider that, while a few authorities consider the primary stage of stuttering to be a function of the organism, and not of its environment; all authorities seem to be of the opinion that the second stage of stuttering involves learningthe learning of (inadequate) patterns of behaviour which were originally intended to "avoid, postpone, disguise, start or release the speech abnormality." (Van Riper.)

It can be argued, therefore, that the principles of learning can be applied to reduce these secondary symptoms of stuttering, if not to the actual elimination of the original "primary" stutter, which may or may not, be a function of learning.

Before discussing how this could be done, a brief outline of the fundamentals of learning is indicated.

Hull (9) (in his "Principles of Behaviour") gives as the four fundamentals of learning, Drive, Cue, Response and Reward.

The Drive-is a strong stimulus which impels the organism to action. It may be primary (physiological) or secondary (acquired). Secondary drives are acquired on the basis of the primary drives, e.g., anxiety and fear are secondary drives based on the primary drive, pain. Without drives the organism does not behave, and hence does not learn.

Cue: The drive compels a person to respond. Cues determine WHEN he will respond, WHERE he will respond, and WHICH response he will make.

Response: The way in which the person responds to a cue, when he is driven to a reward, is his response.

Reward: This is an event which produces a reduction in the drive. Like the drive, it may be primary (physiological) or secondary (acquired) on the basis of a primary drive. Without reward, there is no learning.

To summarise the learning process - the drive impels a response which is determined by a cue. If this response is followed by a reward frequently enough, learning occurs, so that on the presentation of a certain situation (Drive and Cue) a particular response is made.

I have attempted to rephrase elsewhere (10) some of the stuttering experts' theories in terms of these four fundamentals, e.g., Johnson's Theory: 
Drive : To avoid non-fluency-"to avoid expected stuttering"-Johnson.

Cue: "The expectation of stuttering"-Johnson, 'words which cause anxiety about stuttering"-Brown.

Response: "Tension, an expression of the anxiety and an attempt to avoid the anxiety ... an anticipatory hypertonic, avoidance reaction"-Johnson.

Reward: The uttering of the word.

Most rewards can be stated in Fletcher's words as "communication, the basis of Society." To get the word out is the primary aim, or drive, of the stutterer.

The acquisition of secondary symptoms could be described in learning terms as follows:

Communication-to get his words out-is the stutterer's drive. He responds to the cue of a feared word or situation by a "hypertonic" speech effort-i.e., he forces the word out, often using bizarre accompanying movements. Eventually he is rewarded, i.e., he gets the word out. Then there comes into play the "gradient in the effect of reward"i.e., if a number of different responses are made to a cue, and that the last of these responses is followed by reward, the connection to the last response will be strengthened most. Therefore, a movement, a gesture, a vocalisation, which may have nothing to do with the actual utterance of the word, may be "learned" as it was the nearest action in time to the reward response.

The act of stuttering may be specifically reinforced by virtue of its relatively close association with anxiety tension reduction accompanying the removal of $\alpha$ feared word. It seems as if there is a vicious circle where completion of the stuttered act results in a reduction of the anxiety tension evoked by the stimulus word, with consequent reinforcement of stuttering behaviour.

Secondary symptoms appear to be learned by the stutterer to help him get over a block. Especially when first acquired, secondary symptoms probably serve largely as anxietyreducing agents.

If we wish to change the stutterer's response, we must attempt to change either his drives, his cues, or his rewards (or all of these). Established therapies have been directed towards these goals. Mental hygiene and re-evaluation have aimed at changing the stutterer's drives and cues. Negative Practice of secondary symptoms aims at substituting a punishment for a reward when the response of the secondary symptom is made.

I feel that stuttering therapy could be handled with greater confidence if we worked systematically on the basis of learning. The stutterer can be helped to react differently to cues (particularly feared situations) if he is helped to make a better general adjustment (e.g., encouraging "excitatory" traits in "inhibitory" personalities, Salter (11) ; He could learn to respond to situations with relaxation instead of tension (Jacobson's Progressive relaxation (12); Wolpe's reciprocal inhibition and specific desensitisation (12). As in negative practice, his secondary symptoms could acquire a punishment value, rather than $a$ reward value (e.g., as the reward of a secondary stutterer is the utterance of the word, I am attempting to make the stutterer respond to a secondary symptom with a complete silence -the secondary "_____ acquires punishment value by breaking communication, instead of reward value by continuing it).

Once therapists have accepted the principles of learning psychology, the possibilities of systematic therapy are limitless. As Kingdon Ward says "if we accept the factor of heredity we are committed to a passive acceptance of conditions which can never be wholly overcome-the post-natal environment can be modified to some extent." I believe that a scientific manipulation of the environment (drives, cues and rewards) and responses of a learning organism; can be one of our best leads in stuttering therapy.

1. Bluemel, O.S.- "Stammering and Allied Disorders," 1935.

2. Johnson, W.- "Speech Handicapped School Children," 1948.

3. Steill, L.-.' 'Speech and Voice," 1942.

4. Fletcher, J. M.- "The Problem of Stutcring," 1928.

5. Travis-“'Speceh Pathology," 1931.

6. Karlin : Psychosomatic Theory of Stutiering "Jourmal of Speech Diforders," 1947.

i. Van Riper-“'Speech Correction," 1954.

8. Kindon Ward, W.-"Stammering-A Contribution to the Study of its Problems and Treatment," 1941.

9. Hull, C. C.- "Principles of Behaviour," 1954.

10. Marke, M.--"Stuttering Behaviour and Learuing". Thesis presented for B.A. Log. Degree, 1953

11. Salter-“'Gonditioned Reflex Therapy."

12. Jacobson- "Progressive Relaxation."

13. Wolpe-Reciprocal Inhibition as tle Main Basis of Theraputic Effects : "Arch. Neurol, Psychiat." 1954. 